\title{
The Effect of Evidence-Based Guidelines on Nurses, Performance in Respect to Nosocomial Infection at Medical-Surgical and Obstetrician Departments
}

\author{
Mageda A. S. Arafat ${ }^{1}$, Abeer Yahia Mahdy ${ }^{2}$, Mirfat M. L. El-Kashif ${ }^{3, *}$ \\ ${ }^{1}$ Nursing Administration, Faculty of Nursing / Benha University, Egypt \\ ${ }^{2}$ Medical Surgical Nursing departement, Faculty of Nursing / Benha University, Egypt \\ ${ }^{3}$ Maternity, Obstetrics \&Gynecology, Faculty of Nursing / Port Said University, Egypt \\ *Corresponding author: mega_mega27@yahoo.com
}

Received August 19, 2018; Revised October 13, 2018; Accepted October 28, 2018

\begin{abstract}
Background: Nurses are healthcare workers that play an essential role in the control of hospital infection, protect patients from hospital required infection and leads to better control of diseases. As long as, nurses, midwives, and healthcare support workers. Healthcare staff should have an adequate level of performance regarding hospital infection. Aim: Assess the effect of evidence-based guidelines on Nurse's performance in respect to nosocomial infection at medical-surgical and obstetrician department. Subjects and Methods: A pretest-posttest questionnaire design was used in this study to assess the effect of evidence-based guidelines on performance among nurses for infection control at Benha University Hospital. Sample: the total 110 nurses enrolled in this study (60) nurses in the internal medicine department, (30) nurses in the surgical department and (20) nurses in the obstetric department, nurses who their experience at least one year. With different, Age 20- 50 years old had been selected .Results: The present study showed that there were statistically significant differences in the level of knowledge, the practice of infection control methods, nurses attitude regarding nosocomial infection control before and immediately after induction of the guidelines, ( MH7.220, $\mathrm{P}<0.0001 *),\left(\mathrm{MH}=5.555, \mathrm{P}=0.003^{*}\right.$ and $\left.\mathrm{MNP}=0.012 *\right)$ subsequently. The current study demonstrated that before the induction of guidelines, there were statistically significant differences regarding and attitude was $(\mathrm{r}=0.547, \mathrm{p}<0.0001)$. After the induction of the guidelines, the results indicated that the association the association between; knowledge and practice was ( $r=0.308, p<0.0001)$, knowledge and attitude was $(0.207, \mathrm{p}<0.05)$, practice between; knowledge and practice was $(\mathrm{r}=0.170, \mathrm{p}>0.05)$, knowledge and attitude were (0.012, $\mathrm{p}>0.05)$, practice and attitude were $(\mathrm{r}=0.324, \mathrm{p}<0.0001)$. The current study revealed to ( $91.8 \%$ and $81.8 \%)$ conducted not enough medical tests on a regular basis and received not enough vaccinations regarding infection control and prevention respectively. Conclusions: Nurses who received evidence-based guidelines regarding infection prevention showed statistically significant improvement in their performance after the implementation of evidence-based guidelines compared with before implementation. There was the highly significant correlation between before the implementation of evidence-based guidelines but after the implementation of evidence-based practice guidelines; there was non-significant correlation occurred.
\end{abstract}

Keywords: Evidence-Based Guidelines (EBG), nosocomial infection, healthcare-associated infection (HAI)

Cite This Article: Abeer Yahia Mahdy, Mirfat M. L. El-Kashif, and Mageda A. S. Arafat, "The Effect of Evidence-Based Guidelines on Nurses, Performance in Respect to Nosocomial Infection at Medical-Surgical and Obstetrician Departments." American Journal of Nursing Research, vol. 6, no. 6 (2018): 507-514. doi: 10.12691/ajnr-6-6-19.

\section{Introduction}

Evidence-based practice is seen as a way of providing more effective health care and is considered to be vital in the current healthcare climate. However, in many areas of practice specifically in infection control, there is often little or no evidence to back certain practices. Evidence-based practice (EBP) guidelines are the asset of systematically in progress representations commonly depend on the empirical document for assessing health care provider and patients in decision making about an appropriate health care measures in particular clinical matters [1]. As mentioned by [2], several evidence-based methods decreased the rate of healthcare-associated infection (HAI); hand hygiene is by far the most effective method in reducing the prevalence of $\mathrm{HAI}$; percutaneous injuries caused by needles and sharps are responsible for the infection. Besides the evidenced role of hand washing and percutaneous injuries, other non-pharmacological interventions such as cleaner hospital environment have been shown to reduce the rate of HAI significantly. Carrying out of evidence-based practice (EBP) have to 
high-quality secure care, enhanced patient outcomes, and diminished costs. Pay also, EBP authorizes clinicians and leads to higher levels of commitment, teamwork, and job satisfaction $[3,4]$.

Hospital-acquired infection or nosocomial infection is a worldwide problem and remain the most cause of morbidity and mortality among the hospitalized patients and increase an additional cost [5-11]. Regardless of all healthcare professional endeavors across infection control, the infection stays the most consequences of health care and needs more stress. [12] on their research on the assessment of infection control practices in maternity units in Southern Nigeria, they found that uncomplicated delivers were conducted by nurse/midwives, while $91 \%$ (57 facilities) had a doctor providing back-up maternity services, including operative deliveries. As mentioned by [13] hospital-acquired infection defined as the infection that can transfer to patients during hospitalization which was not present on the time of admission. [14] deduced that one every 20 patients suffers from a hospital-acquired infection and leads to the death of 99.000 cases every year. Because nurses is one of the healthcare workers who play an essential role in control of hospital infection and spend the maximum of their time with patients; the essential role of the nurses as health care providers is to protect patients from hospital-acquired infection in the time of hospitalization or while in a health care set up by maintaining the environment free from infection and providing a high-quality nursing care. Lack of knowledge, bad attitudes and poor practices amongst nurses in the prevention and control of infections can lead to hospital-acquired infections [15]. Subsequently, they should have an optimal level of knowledge, practice, and attitude in the prevention of infection. [16] showed that large percentages of nursing students have a low level of information, a moderate practice as well as a positive attitude about infection control.

The shortage of effective preventive measures and evidence-based practice is not considered the significant problem, but the most of healthcare professionals improperly use these precautions. Subsequently, the stress is to improve this negligence in the behavior of health care workers toward the infection control measures. Regarding levels of infection prevention, [15] reported that nurses had an undesirable level of practice and exposing the patients to infection-related diseases. Measures of infection control include, follow aseptic techniques of hand hygiene.

National Healthcare Safety Network with Center for Disease Control (CDC) for surveillance nosocomial infection sites was classified into thirteen types, fifty sites for infection, which are based on criteria as clinical and biological. The common sites include urinary tract infections (UTI), meningitis, respiratory, surgical and soft tissue, gastrointestinal infections, [17] invasive devices and all medical instruments, Moreover, guidelines for the control of UTI. Decrease compliance with the guidelines; cause the increase in nosocomial infections. Control and prevention guidelines have been developed. Training of healthcare staff, especially nurses, is extremely important for the guideline of infection $[18,19]$. HCAI Are still uncontrollable. The control of microorganisms responsible for it is much needed as they cause significant economic as well as production loss. The infection control practices compliance can avoid these infections transmission in settings through healthcare staff. Besides, there is also the greatest need for the best performance should be shared among hospitals to stop the spread of nosocomial infection [20].

\subsection{The Aim of the Study}

The current study was aimed to evaluate the effect of evidence-based guidelines on Nurse's performance in respect to nosocomial infection control at medical-surgical and obstetrician department.

\subsection{Research Hypothesis}

1. The post means knowledge scores of the nurses who follow the evidence-based guidelines toward nosocomial infection control measures will be increased.

2. The post means practices scores of the nurses who will follow the evidence-based guidelines toward nosocomial infection control measures will be improved.

3. The attitude of the nurses who will be following the evidence-based guidelines toward nosocomial infection control measures will be improved.

4. There are strong positive correlations among knowledge attitude and performance will show after following nosocomial infection control measures

5. There is a positive correlation between hospital capability and nurses performance

\section{Materials and Methods}

\subsection{Research Design \& Setting}

Quasi-experimental study design was used

\subsection{Setting}

This study was carried out at Benha University Hospital in The Internal Medicines, surgical and obstetric departments.

\subsection{Subjects and Sample}

Staff nurses working at the previously mentioned departments at Benha University Hospital within the period of the study. In total 110 nurses enrolled in this study (60) nurses in the internal medicine department, (30) nurses in the surgical department and (20) nurses in the obstetric department. They had been selected according to the following criteria:-

Inclusion criteria:- nurses who their experience at least one year. With different, Age 20- 50 years old.

Exclusion criteria:- Whom aged more than 50 years and less than 20 years.

\subsection{Tools of Data Collection}

The tools of this study were two tools which included:-

The first tool: it includes two parts.

1st part; recorded nurses' demographic and professional characteristics (age, gender, educational level, qualifications, marital status, unit of activity, a history of infection control training, etc.); 
2nd part The interview questionnaire sheet: was designed by the researchers after reviewing related literature Also it helped the researchers to develop the guidelines. It was conducted in a simple Arabic form in order to prevent misunderstanding. The 2nd part consists of three subsections: the 1st subsection; nurses knowledge about nosocomial infection including four items about the nature of infection, mode of transmission, prevention of infection and nursing role. The 2nd subsection, nurses practice including, including 35 items measuring practice about the adoption of preventive behaviors; hand washing, dressing skills, when to use eye protector and facial mask, precautions with needles and sharp materials and how to collect contaminated sheets. The 3rd subsection; nurses attitude, including ten items measuring perceived threat by nurses about HAI (healthcare-associated infections) of nurses and patients and perceived benefits by patients about the observation of standard precautions.

Scoring system:- In the knowledge subsection, each correct answer to the items was scored 3, each wrong answer was scored 2, and I do not know the answer was scored 1 . The practice subsection was comprised of 35 items rated on a 3-point Likert scale from 1 to 3 (not applicable=1, Disagree=2, Agree=3). Items in the attitude subsection were also rated on a three-point Likert scale. In evaluating the data in both sections of the knowledge and practice of nurses in the context of standard precautions, the scores of nurses were categorized as low, medium, and good. Scores less than $50 \%$ were considered as poor, scores between 50 and 75 were considered as average, and scores more than 75 were considered as good.

The second tool: consist of a questionnaire on the availability of the capabilities and needs of preventing infection within the unit including 20 items measuring the availability of the capabilities and needs of preventing infection within the medical, surgical and obstetric units each yes and enough answer was scored 3, each yes and not enough answer was scored 2 and no more answer was scored 1. Finally, the scores were calculated in percent - the number of correct answers multiplied by 60 divided by the total number of items.

\subsection{Content Validity of the Tools}

Content validity comprehensiveness of tools was done to check the relevancy, coverage, and clarity of the questions, by five experts in the field of the study. One assistant professor, one lecturer of Medical-Surgical Nursing and one obstetrician in the Faculty of Nursing at Benha and Port Said Universities, and one professor, one lecturer of nursing administration in the Faculty of Medicine, Benha and Port Said University. Accordingly, modifications were done, and the final form was developed.

\subsection{Pilot Study}

The questionnaire was pilot tested with a group of (10\%) of nurses in order to evaluate the developed tools for the visibility, clarity, and applicability of the designed form in providing the required data and the necessary modification was done, and they excluded from the original data

\subsection{Fieldwork}

The study was conducted after obtaining official permission to conduct this study was obtained from the heads of mentioned Units. The researchers explained the purpose of the study to heads of departments and nurses; to obtain their cooperation. Ethical consideration explained and ensured confidentiality after that nurses' oral informed consent obtained. Data were collected via interview questionnaires and the availability of the capabilities and needs of preventing infection. Collection of data for this study was carried out in the period from the starting of the may2017to end of September 2017. A convenient sample according to the previous criteria was selected. The researchers developed tools after reviewing of related literature and were tested for content validity by experts' in Nursing. The pre-test was done for ten days, then guideline implementation was done for two months, and immediate post-test was done. The time needed for the completion of the interview was between $20-30$ minutes.

The guidelines included different sessions developed by the researchers to improve nurses' performance related to nosocomial infection control. The guideline involved (3) sessions, each session had repeated for three times per week. The guideline was implemented for a group of nurses entailing (12 nurses) according to working circumstances. After the implementation of the guidelines, the immediate post-test was done to the studied nurses' performance by the same format of the pre-test using tools to evaluate the effect of the implemented guidelines.

\subsection{Ethical Consideration}

Before the start of data collection, ethical approval for the conduction of the research was obtained. Informed consent of nurses participation was taken, and they informed that participation was voluntary and they may and confidentiality of privacy of the nurse).

\subsection{Statistical Analysis}

The original data were analyzed by using SPSS system files (SPSS package version 19, Chicago, USA). Analysis and interpretation of data were conducted.

The following statistical measures were used: Descriptive statistics including frequency, distribution, mean and standard deviation were used to describe different characteristics. Kolmogorov - Smirnov test was used to examine the normality of data distribution. Univar ate analyses including Chi-Square test, Monte Carlo test and Fisher's Exact test were used to test the significance of results of qualitative variables. Moreover, Marginal Homogeneity test and Mac Nemar test were used to test the significance of the paired qualitative variables. The linear correlation was conducted to show a correlation between knowledge, practice and attitude scores among the studied nurses. The significance of the results was at the $5 \%$ level of significance.

The significance of the results was at the $5 \%$ level of significance tested. 


\section{Results}

Table 1: show nurses recruited from internal medicine (54.5\%), they are played more than have of the sample. The mean age was (37.1 \pm 6.5$)$, the majority of them were married (90.9\%). Largr percent of them (54.5\%) are working in internal medicine department (Figure 1). More than half of nurses (55.5\%) having nursing Institute, (77.2\%) of studied nurses were bedside nurses (Figure 2). Their experience was above ten years, about one third (31.8\%) work duration (9.6 \pm 3.5$)$. More than half (58.2 \%) of nurses had training on infection control.

Table 2: Demonstrated that the most massive percent of studied nurses (39.1\%) had fair knowledge before induction of the guidelines .but after induction of the evidence-based guidelines they were good $(80 \%)$ in knowledge about nosocomial infection. About their practice of infection control methods, the results showed that, before induction of guidelines, most of the nurses had a reduced level $(93.6 \%)$, but after the induction of guidelines this percent is decreased to (66.4\%). The results indicated that near three quarters (73.6 \%) of studied nurses had a negative attitude in infection control $(\mathrm{P}=0.012)$.

Table 3: Reported that before the induction of guidelines, the association between; knowledge and practice was $(\mathrm{r}=0.308, \mathrm{p}<0.0001)$, knowledge and attitude was $(0.207, \mathrm{p}<0.05)$, practice and attitude was $(\mathrm{r}=0.547$, $\mathrm{p}<0.0001)$. After the induction of the guidelines, the results indicated that the association between; knowledge and practice was $(\mathrm{r}=0.170, \mathrm{p}>0.05)$, knowledge and attitude were $(0.012, \mathrm{p}>0.05)$, practice and attitude were $(\mathrm{r}=0.324, \mathrm{p}<0.0001) .57 .4 \%$ of the women within the age group $25-<35$ have negative culture.

As shown in the Table 4, near half (49.1\%) of studied nurses reported non-committee to prevent infection in the hospital was present, $(52.7 \%)$ of them reported that the presence of manuals in the unit on infection prevention methods was not enough. The current study revealed to (91.8\% and $81.8 \%)$ conducted not enough medical tests on a regular basis and received not enough vaccinations regarding infection control and prevention respectively.

Table 1. Distribution of the study group according to their socio-demographic characteristics

\begin{tabular}{|c|c|c|}
\hline \multirow{2}{*}{ Socio-demographic Characteristics } & \multicolumn{2}{|c|}{ Studied nurses $(n=110)$} \\
\hline & No. & $\%$ \\
\hline \multicolumn{3}{|l|}{ Age (years) } \\
\hline $20-<30$ & 14 & 12.7 \\
\hline $31-<40$ & 59 & 53.6 \\
\hline $40 \leq$ & 37 & 33.7 \\
\hline Mean \pm SD & \multicolumn{2}{|c|}{$37.1 \pm 6.5$} \\
\hline \multicolumn{3}{|l|}{ Marital status } \\
\hline Single & 10 & 9.1 \\
\hline Married & 100 & 90.9 \\
\hline \multicolumn{3}{|l|}{ Educational level } \\
\hline Nursing diploma & 37 & 33.6 \\
\hline Nursing institute & 61 & 55.5 \\
\hline Bachelor degree or postgraduate studies & 12 & 10.9 \\
\hline \multicolumn{3}{|l|}{ Duration of experience (years) } \\
\hline $1-<5$ & 14 & 12.7 \\
\hline $5-<10$ & 35 & 31.8 \\
\hline $10 \leq$ & 61 & 55.5 \\
\hline Mean \pm SD & & \\
\hline \multicolumn{3}{|l|}{ Previous training on infection control } \\
\hline Yes & 64 & 58.2 \\
\hline No & 46 & 41.8 \\
\hline
\end{tabular}

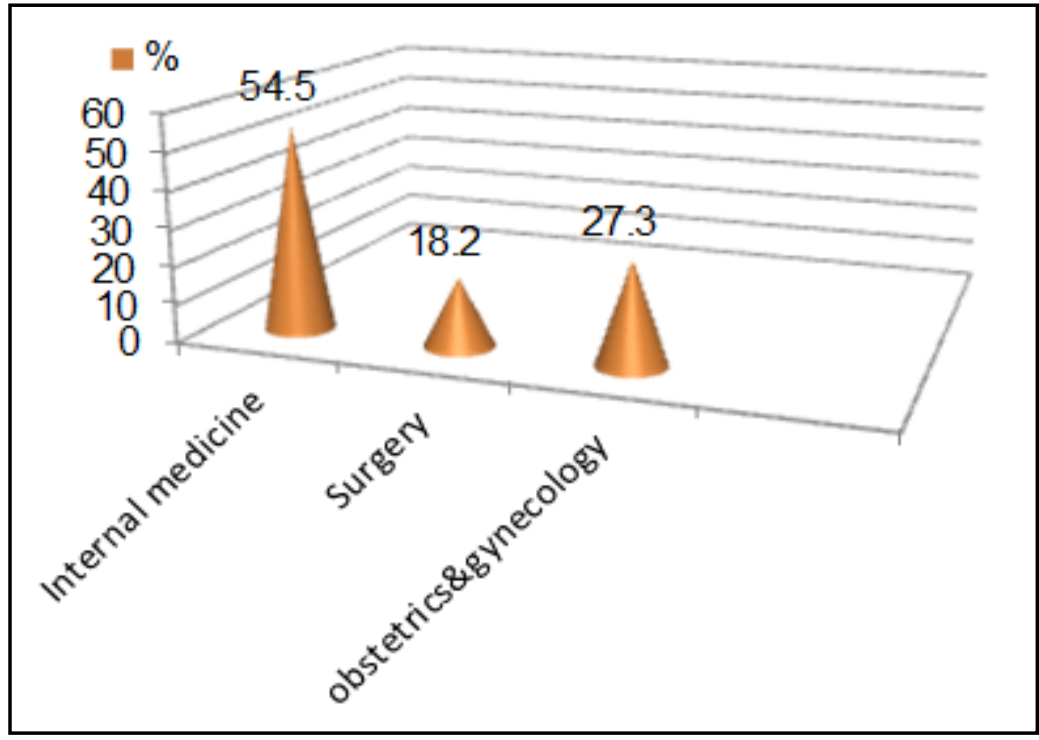

Figure 1. Distribution of the study group according to their department 


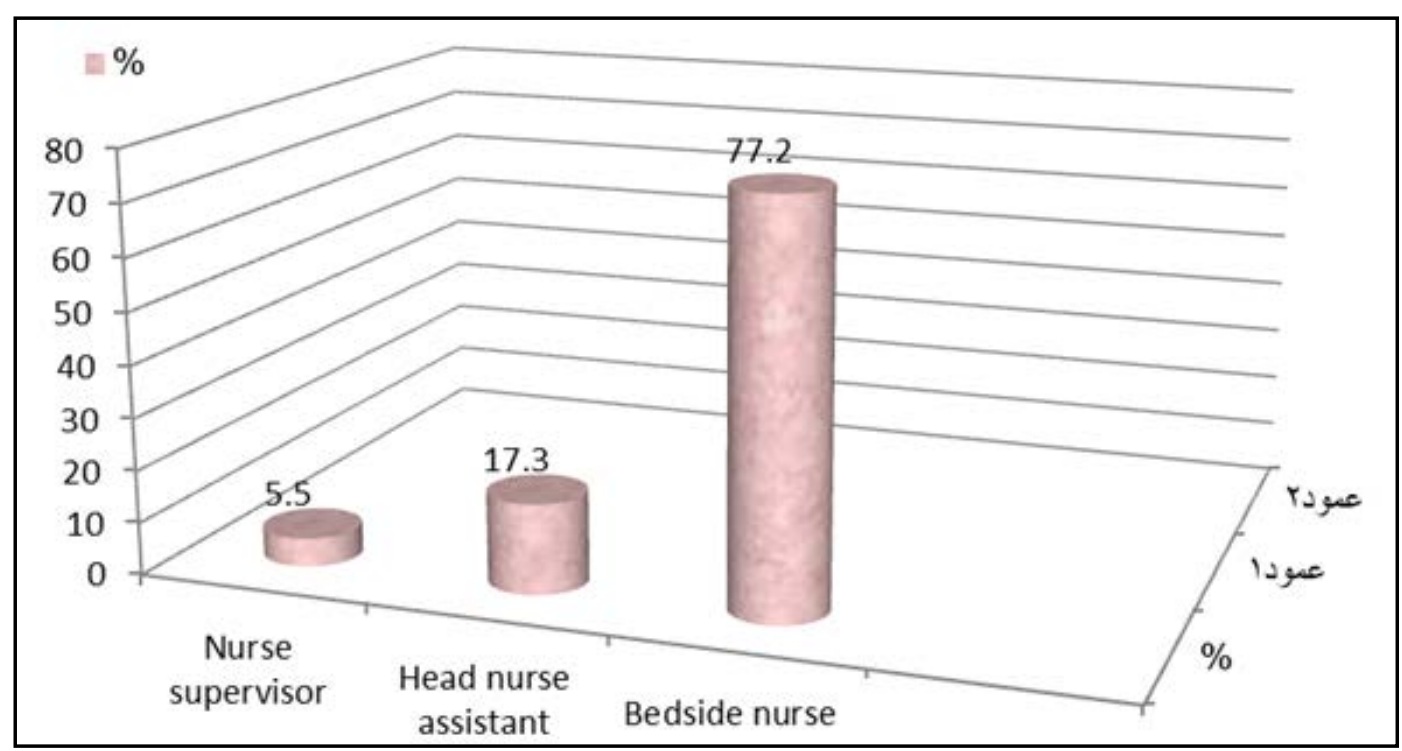

Figure 2. Distribution of the study group according to their job carrier

Table 2. Comparison between knowledge, attitude, and practice of nurses before and after applying the evidence-based guidelines

\begin{tabular}{|c|c|c|c|c|c|c|}
\hline \multirow{2}{*}{ Scores } & & \multicolumn{2}{|c|}{ Before induction of guidelines } & \multicolumn{2}{|c|}{ After induction of guidelines } & \multirow{2}{*}{ Significance } \\
\hline & & No. & $\%$ & No. & $\%$ & \\
\hline \multicolumn{7}{|l|}{ Knowledge about infection } \\
\hline \multirow[t]{3}{*}{ Nature of infection } & Poor & 46 & 41.8 & 32 & 29.1 & \multirow{3}{*}{$\begin{array}{c}\mathrm{MH}=2.111 \\
\mathrm{P}=0.035^{*}\end{array}$} \\
\hline & Fair & 35 & 31.8 & 49 & 44.5 & \\
\hline & Good & 29 & 26.4 & 29 & 26.4 & \\
\hline \multirow[t]{2}{*}{ Mode of transmission } & Poor & 41 & 37.3 & 23 & 20.9 & \multirow{2}{*}{${ }^{\mathrm{MN}} \mathrm{P}<0.0001 *$} \\
\hline & Good & 69 & 62.7 & 87 & 79.1 & \\
\hline \multirow[t]{2}{*}{ Prevention of infection } & Poor & 17 & 15.5 & 7 & 6.4 & \multirow{2}{*}{${ }^{\mathrm{MN}} \mathrm{P}=0.002 *$} \\
\hline & Good & 93 & 84.5 & 103 & 93.6 & \\
\hline \multirow[t]{2}{*}{ Role of the nurse } & Poor & 84 & 76.4 & 27 & 24.5 & \multirow{2}{*}{${ }^{\mathrm{MN}} \mathrm{P}<0.0001 *$} \\
\hline & Good & 26 & 23.6 & 83 & 75.5 & \\
\hline \multirow[t]{3}{*}{ Total knowledge level } & Poor & 25 & 22.7 & 1 & 0.9 & \multirow{3}{*}{$\begin{array}{l}\mathrm{MH}=7.220 \\
\mathrm{P}<0.0001^{*}\end{array}$} \\
\hline & Fair & 43 & 39.1 & 21 & 19.1 & \\
\hline & Good & 42 & 38.2 & 88 & 80.0 & \\
\hline \multicolumn{7}{|l|}{ Practice } \\
\hline \multirow[t]{3}{*}{ Hand washing } & Poor & 95 & 86.4 & 72 & 65.5 & \multirow{3}{*}{$\begin{array}{l}\mathrm{MH}=4.849 \\
\mathrm{P}<0.0001^{*}\end{array}$} \\
\hline & Fair & 11 & 10.0 & 30 & 27.3 & \\
\hline & Good & 4 & 3.6 & 8 & 7.3 & \\
\hline \multirow[t]{3}{*}{ Dressing skills } & Poor & 81 & 73.6 & 64 & 58.2 & \multirow{3}{*}{$\begin{array}{l}\mathrm{MH}=5.013 \\
\mathrm{P}<0.0001^{*}\end{array}$} \\
\hline & Fair & 20 & 18.2 & 20 & 18.2 & \\
\hline & Good & 9 & 8.2 & 26 & 23.6 & \\
\hline \multirow{2}{*}{ Use of eye protector and facial mask } & Poor & 108 & 98.2 & 108 & 98.2 & \multirow{2}{*}{${ }^{\mathrm{MN}} \mathrm{P}=1.0$} \\
\hline & Good & 2 & 1.8 & 2 & 1.8 & \\
\hline \multirow{3}{*}{$\begin{array}{l}\text { Precautions with needles and sharp } \\
\text { materials }\end{array}$} & Poor & 79 & 71.8 & 35 & 31.8 & \multirow{3}{*}{$\begin{array}{l}\mathrm{MH}=7.660 \\
\mathrm{P}<0.0001^{*}\end{array}$} \\
\hline & Fair & 31 & 28.2 & 37 & 33.6 & \\
\hline & Good & 0 & 0.0 & 38 & 34.5 & \\
\hline \multirow{3}{*}{ Collection of contaminated sheets } & Poor & 73 & 66.4 & 22 & 20.0 & \multirow{3}{*}{$\begin{array}{l}\mathrm{MH}=7.660 \\
\mathrm{P}<0.0001^{*}\end{array}$} \\
\hline & Fair & 28 & 25.5 & 43 & 39.1 & \\
\hline & Good & 9 & 8.2 & 45 & 40.9 & \\
\hline Dealing with blond samples & Poor & 93 & 84.5 & 66 & 60.0 & \\
\hline Deding will Dioud salnples & Fair & 14 & 12.7 & 24 & 21.8 & $\begin{array}{l}\mathrm{MH}=5.416 \\
\mathrm{P}<0.0001^{*}\end{array}$ \\
\hline & Good & 3 & 2.7 & 20 & 18.2 & \\
\hline Total practice score & Poor & 103 & 93.6 & 73 & 66.4 & \\
\hline & Fair & 5 & 4.5 & 29 & 26.4 & $\begin{array}{c}\mathrm{MH}=5.555 \\
\mathrm{P}=0.003^{*}\end{array}$ \\
\hline & Good & 2 & 1.8 & 8 & 7.3 & \\
\hline Attitude & & & & & & \\
\hline Attitude level & Negative & 93 & 84.5 & 81 & 73.6 & \\
\hline & Positive & 17 & 15.5 & 29 & 26.4 & ${ }^{\mathrm{NiII}} \mathrm{P}=0.012^{*}$ \\
\hline
\end{tabular}

MH: Marginal Homogeneity test Standard value, ${ }^{\mathrm{MN}} \mathrm{P}$ : P-value for Mc Nemar test *significant at $\mathrm{P} \leq 0.05$. 
Table 3. Correlations between scores of knowledge, attitude and practice before and after the program

\begin{tabular}{|l|l|c|c|c|c|c|c|}
\hline \multirow{2}{*}{ Scores } & \multicolumn{2}{c|}{ Knowledge } & \multicolumn{2}{c|}{ Practice } & \multicolumn{2}{c|}{ Attitude } \\
\cline { 3 - 8 } & Knowledge score & $\mathrm{r}$ & $\mathrm{P}$ & $\mathrm{r}$ & $\mathrm{P}$ & $\mathrm{r}$ & $\mathrm{P}$ \\
\hline Before the program & - & - & 0.308 & $0.001^{*}$ & 0.207 & $0.030^{*}$ \\
\hline & Practice score & 0.308 & $0.001^{*}$ & - & - & 0.547 & $<0.0001^{*}$ \\
\hline & Attitude score & 0.207 & $0.030^{*}$ & 0.547 & $<0.0001^{*}$ & - & - \\
\hline & & & & & & & \\
\hline After the program & Knowledge score & - & - & 0.170 & 0.075 & 0.012 & 0.902 \\
\hline & Practice score & 0.170 & 0.075 & - & - & 0.324 & $0.001^{*}$ \\
\hline & Attitude score & 0.012 & 0.902 & 0.324 & $0.001^{*}$ & - & - \\
\hline
\end{tabular}

r: Pearson Correlation Coefficient, *significant at $\mathrm{P} \leq 0.05$.

Table 4. Distribution of availability of non-contagion prevention capabilities and needs within the working unit

\begin{tabular}{|c|c|c|c|c|c|c|}
\hline \multirow{2}{*}{ Non-contagion prevention capabilities } & \multicolumn{2}{|c|}{ None } & \multicolumn{2}{|c|}{ Yes/not enough } & \multicolumn{2}{|c|}{ Yes/enough } \\
\hline & No. & $\%$ & No. & $\%$ & No. & $\%$ \\
\hline A committee to prevent infection in hospital & 54 & 49.1 & 41 & 37.3 & 15 & 13.6 \\
\hline Manuals in the unit on infection prevention methods & 39 & 35.5 & 58 & 52.7 & 13 & 11.8 \\
\hline Medical tests on a regular basis & 7 & 6.4 & 101 & 91.8 & 2 & 1.8 \\
\hline The hospital provides nurses with any vaccinations regarding infection control and prevention & 8 & 7.3 & 90 & 81.8 & 12 & 10.9 \\
\hline Wash basins are available & 19 & 17.3 & 50 & 45.5 & 41 & 37.3 \\
\hline Soap is available for hand washing & 59 & 53.6 & 38 & 34.5 & 13 & 11.8 \\
\hline Enough alcohol to rub hands & 38 & 34.5 & 63 & 57.3 & 9 & 8.2 \\
\hline Means or materials to dry the hands after washing them & 29 & 26.4 & 53 & 48.2 & 28 & 25.5 \\
\hline A suitable disinfectant to clean the skin of the patient & 23 & 20.9 & 59 & 53.6 & 28 & 25.5 \\
\hline Safety boxes available for disposal of acute waste & 32 & 29.1 & 58 & 52.7 & 20 & 18.2 \\
\hline An autoclave & 29 & 26.4 & 49 & 44.5 & 32 & 29.1 \\
\hline Hats & 9 & 8.2 & 53 & 48.2 & 48 & 43.6 \\
\hline Surgical mask & 22 & 20.0 & 59 & 53.6 & 29 & 26.4 \\
\hline Protective gaskets & 35 & 31.8 & 50 & 45.5 & 25 & 22.7 \\
\hline Surgical gowns & 25 & 22.7 & 57 & 51.8 & 28 & 25.5 \\
\hline Gloves nonsterile & 15 & 13.6 & 55 & 50.0 & 40 & 36.4 \\
\hline Durable gloves & 8 & 7.3 & 67 & 60.9 & 35 & 31.8 \\
\hline Eye protectors & 26 & 23.6 & 51 & 46.4 & 33 & 30.0 \\
\hline Protective shoes for the foot & 22 & 20.0 & 64 & 58.2 & 24 & 21.8 \\
\hline Furniture for the family & 16 & 14.5 & 76 & 69.1 & 18 & 16.4 \\
\hline
\end{tabular}

\section{Discussion}

This study aims to assess the effect of evidence-based guidelines on nurses' performance at Benha University Hospital. The study on the compliance to infection prevention and control guidelines among health care workers at Mnazi Mmoja hospital Zanzibar revealed that prevention of infection and control of hospital-acquired infection depends on the level of knowledge, practice, and commitment provided by healthcare organizations to control of hospitalacquired infection [21]. From the present study, it is showed that a large percent of studied nurses had poor knowledge regarding nosocomial infection control before induction of the guidelines. This may be due to hospital policy in which no interest there worker by infection control and not updated to their performances. What this agree with the study [22] revealed that (43\%) of the participants had poor knowledge and also another study mentioned that only (28\%) of nurses had good knowledge on infection control principles [23]. In the same direction [24] indicated that more than half of the studied nurses have inaccurate knowledge about catheter-related bloodstream infections and factors associated complications in pre-intervention phase and the majority of them improved their knowledge level immediately after implementation of teaching guidelines, with a highly statistically significant difference.

The evidence and data from analyzed studied pointed to several practices to reduce HAI. For prevention of HAI; number of intervention and practices were identified as; hand washing, use of eye protectors and facial masks, dressing skills and dealing with blood samples Understanding despite (58.2 \%) of them attend previous training programs regarding to infection prevention and control, they need to update their knowledge of infection control through persistent educational programs. The results of the study on the Assessment of infection control practices in maternity units in Southern Nigeria revealed the strategic approach for managing and preventing infections in public and private delivery health facilities in Edo state was lack [12]. The guidelines for the control of infection were not clear although several guidelines develop benchmarks and standards for infection control in maternity units for developing countries $[25,26]$. the study focused on the importance of improving, education, training, prevention and control practices [27]. Moreover it was recommended updating knowledge and practice of nurses through continuous in-service educational programs emphasizing 
the importance of the evidence-based practices of infection control [28]. In the same direction, [29] indicated that infection control and standards precautions are evidence-based practices that can reduce the risk of transmission of microorganism. According to WHO the big gap between the cumulative knowledge and the attitude and practice toward infection control measures still exist. This may be due to insufficient resources and inability to apply knowledge in a real situation [30].

The current study (Table 4), revealed that near half $(49.1 \%)$ of studied nurses reported non-committee to prevent infection in the hospital was present, (52.7\%) of them reported that the presence of manuals in the unit on infection prevention methods was not enough. The current study revealed to $(91.8 \%$ and $81.8 \%)$ conducted not enough medical tests on a regular basis and received not enough vaccinations regarding infection control and prevention respectively and this was supported by the study of [15] who mentioned that (76.4 \%) of nurses did not receive appropriate vaccinations regarding infection control and prevention. Furthermore, most of the studied nurses pointed to that protective supplies and facilities not accessible and not enough all time such as; (Wash basins, soap, enough alcohol to rub hands, materials to dry the hands after washing them. Also, a suitable disinfectant to clean the skin of the patient, safety boxes available for disposal of acute wastes, an autoclave, surgical mask, protective gaskets, hats, surgical gowns, gloves, eye protectors as well as protective shoes for the foot). Thus nurses and also patients are predisposed to hospital-acquired infection. This was in agreement with [31] they deduced that $(34.5 \%)$ of hospital-acquired infection were from critical care units. The current study (Table 4), revealed that near half (49.1\%) of studied nurses reported non-committee to prevent infection in the hospital was present, $(52.7 \%)$ of them reported that the presence of manuals in the unit on infection prevention methods was not enough. The current study revealed to $(91.8 \%$ and $81.8 \%$ ) conducted not enough medical tests on a regular basis and received not enough vaccinations regarding infection control and prevention respectively and this was supported by the study of [15] who mentioned that (76.4\%) of nurses did not receive appropriate vaccinations regarding infection control and prevention. Furthermore, most of the studied nurses pointed to that protective supplies and facilities not accessible and not enough all time such as; (Wash basins, soap, enough alcohol to rub hands, materials to dry the hands after washing them. Also, a suitable disinfectant to clean the skin of the patient, safety boxes available for disposal of acute wastes, an autoclave, surgical mask, protective gaskets, hats, surgical gowns, gloves, eye protectors as well as protective shoes for the foot). Thus nurses and also patients are predisposed to hospital-acquired infection. This was in agreement with [26] they deduced that (34.5\%) of hospital-acquired infection were from critical care units.

\section{Conclusion}

We concluded from the current study that nurses who received evidence-based guidelines regarding infection prevention showed statistically significant improvement in their performance after the implementation of evidencebased guidelines compared with before implementation. There was a highly significant correlation between before the implementation of evidence-based guidelines but after the implementation of evidence-based practice guidelines; there was non-significant correlation occurred.

\section{Recommendations}

We recommended

1-The need for involving the current EB guidelines in educational curricula and providing continuous educational programs for healthcare workers to help them in improving their knowledge.

2-Nursing managers and the infection control team should plan for periodic educational and training programs based on EBP.

3-Enhances hospital needs and capabilities to meet infection control

\section{References}

[1] Khamis, W.B., Wambura, C.M. \& Verma, A. (2014). Compliance to infection prevention and control guidelines among health care workers at Mnazi Mmoja hospital Zanzibar. IMTU Medical journal, 5:34-38.

[2] Mauldin PD, Salgado CD, Hansen IS, Durup DT, Bosso JA. (2010). Attributable hospital cost and length of stay associated with health care-associated infections caused by antibioticresistant gram-negative bacteria. Antimicrob Agents Chemother.; 54: 109-115.

[3] Llata E,Gaynes RP, Fridkin S. (2009). Measuring the scope and magnitude of hospital-associated infection in the United States: the value of prevalence surveys. Clin Infect Dis.; 48: 14341440 .

[4] Murni IM, Duke T, Kinney S, Daley AJ, Soenarto Y. (2014). Reducing hospital-acquired infections and improving the rational use of antibiotics in a developing country: an effectiveness study. Arch DisChild.; 0: 1-6.

[5] Bayoumi, M., H., \& Mahmoud, N., F., (2017). Effect of education program on nurses' knowledge and practice regarding care of central venous line in pediatric hemodialysis: evidence-based practice guidelines. Egyptian Nursing Journal vol.14, issue, 2: pages: 87-99.

[6] Huis A, van Achterberg T, de Bruin M, Grol R, Schoonhoven L, Hulscher M. A. (2012). Systematic review of hand hygiene improvement strategies: a behavioral approach. Implement Sci.; 7: 1-14. Cross Ref Google Scholar.

[7] Kadium M.J., (2015). Improving nurses' knowledge to reduce catheter-related bloodstream infection in Hemodialysis Unit. Published Doctoral of Nursing Practice, Walden University, College of Health Sciences; 2016. pp. 5-23.

[8] Manisha Jain, Vinita Dogra, Bibhabati Mishra, Archana Thakur, Poonam Sood Loomba. (2012). Infection control practices among doctors and nurses in a tertiary care hospital department of Microbiology, G.B. Pant Hospital, New Delhi, India.

[9] Mehta R, Mavalankar DV, Ramani KV, et al (2011). Infection control in delivery care units, Gujarat state, India: a needs assessment, BMC Pregnancy and Childbirth, vol. 11 pg. 37.

[10] Nelson RE, Jones M, Liu CF, Samore MH, Evans ME, Graves N, et al. (2015). The impact of healthcare-associated methicillinresistant Staphylococcus aureus infections on post-discharge healthcare costs and utilization. Infect Control Hosp Epidemiol.; 36: 534-42.

[11] Okonofua, F., Okpokunu, E., Aigbogun, O., Nwandu, C., Mokwenye, C., Kanguru, L., \& Hussein J. (2012). Assessment of infection control practices in maternity units in Southern Nigeria. International Journal for Quality in Health Care, Volume 24, Issue 6, 1 December 2012, Pages 634-640. 
[12] PDF) Nosocomial infections and their control strategies. (2018). Available from:

https://www.researchgate.net/publication/277664436_Nosocomial _infections_and_their_control_strategies [accessed Sep 22].

[13] WHO. (2010). WHO best practices for injections and related procedures toolkit WHO/EHT/10.02.

[14] Chitlmwango P.C. (2017): Knowledge, attitudes and practices of nurses in infection prevention and control within a tertiary hospital in Zambia, submitted partial fulfilment of the requirements for the degree of Masters of Nursing Science Stellenbosch University https://scholar.sun.ac.za.

[15] Darawad MW, Al-Hussami M (2013). Jordanian nursing students' knowledge of, attitudes towards, and compliance with infection control precautions. Nurse Educ Today. Jun; 33(6): 580-3.

[16] Deshmukh M, Shinde M (2014). Impact of structured education on knowledge and practice regarding venous access device care among nurses. Int J Sci 3: 895-901.

[17] Raka L, Zoutman D, Mulliqi G, Krasniqi S, Dedushaj I, Raka N, et al.; (2006). Prevalence of nosocomial infections in high-risk units in the university,.clinical center of Kosova...nfect Control Hosp Epidemiol 27(4): 421-3.

[18] Cardo D, Dennehy P. H, Halverson P, Fishman N, Kohn M, Murphy C. L, Whitley R. J. (2010). Moving toward elimination of healthcare-associated infections: a call to action. Infection Control.; 31: 1101-1105.

[19] Stone PW, Herzig CTA, Pogorzelska-Maziarz M, Carter E, Bjarnadottir, RI, Semeraro PK, et al.; (2015). Understanding infection prevention and controlin nursing homes: a qualitative study. Geriatr Nurs.

[20] Allegranzi B, Gayet-Ageron A, Damani N, Bengaly L, McLaws M-L, Moro M-L, Memish Z, Urroz O, Richet H, Storr J, Donaldson L, Pittet D. (2013). Global Implementation of WHO’s multimodal strategy for Improvement of hand-hygiene: a quasi-experimental study. Lancet Infect Dis.; 13: 843-51. Cross Ref Pub Med Google Scholar.

[21] Kim, S. C., Ecoff, L., Brown, C. E., Gallo, A. M., Stichler, J. F., \& Davidson, J. E. (2017). Benefits of a regional evidence-based practice fellowship program: A test of the ARCC Model. Worldviews on Evidence-Based Nursing, 14(2), 90-98.

[22] Sarani, H., Balouchi, A., Masinaeinezhad, N., \& Ebrahimitabs (2015). Knowledge, Attitude and Practices of Nurses about Standard Precaution for Hospital Acquired Stellenbosch University https://scholar.sun.ac.za Infection in Teaching Hospitals Affiliated to Zabol University of Medical Science. Global Journal of health science.

[23] Tirivanhu, C., Ancia, M. \& Petronella, S. (2014). Barriers to infection prevention and control practice among nurses at Bindura provincial hospital, Zimbabwe. Journal of nursing and health science 1(3): 69-73.

[24] Brusaferro S, Arnoldo L, Cattani G, Fabbro E, Cookson B, Gallagher R, et al.. (2015), Harmonizing and supporting infection control training in Europe. Hosp Infect, 89, (4): 351-6.

[25] Melnyk, B. M., Fineout-Overholt, E., Giggleman, M., \& Choy, K. (2017). A test of the ARCC C _ model improves implementation of evidence-based practice, healthcare culture, and patient outcomes. Worldviews on Evidence-Based Nursing, 14(1), 5-9.

[26] Razine, R., Azzouzi, A., Barkat, R., Khoudri, I., Hassouni, F., Chefchaoun, A.C., \& Abougal. (2012). Prevalence of hospital acquired infections in the university medical center of Rabat, Morocco. International archives of medicine 5: 26.

[27] (WHO) (2015). Draft global action plan on antimicrobial resistance. Available at: http://apps.who.int/gb/ebwha/pdf_files/WHA68/A68_20en.pdf?ua $=1$.

[28] Ghalya, H.A. \& Ibrahim, Y. (2014). Knowledge, Attitudes and Sources of information among Nursing Students towards Infection Control and Standard Precautions. Life Science Journal 11(9).

[29] Gurley ES, Zaman RU, Sultana R, Bell M, Fry AM, Srinivasan A. Rahman M, Rahman MW, Hossain MJ, Luby SP. (2010). Rates of hospital acquired respiratory ilness in Bangladesh Tertiarty Care Hospitals: results from a low-cost pilot surveillance strategy. Clin Infect Dis.; 50: 1084-90. Cross Ref Pub Med Google Scholar.

[30] WHO. (2016). Patient safety Ndola Central Hospital, Zambia in partnering with Guy's and St. Thomas' Foundation Trust, London. Available at; http://www.who.int/patientsafety/implementation/apps/firstwave/ndola-london/en/.

[31] Shrestha R. (2013). Impact of educational intervention on nurses' knowledge regarding care of patients with central venous line. J Kathmandu Med Coll 2: 3.

[32] El-Nemr WA, Fahmy HH, Abed-El Razek GM, Abed El Salam NM (2013). An interventional study to decrease central venous catheter related blood stream infection in intensive care units at Zagazig University Hospital. Zagazig University Med J 19: 492-507.

[33] Fashafsheh, I., Ayed, A., Eqtait, F. \& Harazneh, L. (2015). Knowledge and Practices of Nursing Staff towards Infection Control Measures in the Palestinian Hospitals. Journal of Education and Practice 6(4): 79-90.

[34] Pittet D, Allegranzi B, Storr J, et al. (2008). Infection control as a major World Health Organization priority for developing countries, J Hosp Infect, vol. 68 (pg. 285-92).

[35] Pegram A, Bloomfield J. Infection prevention and control. Nurs Stand. 29(29): 37-42. 